IZA DP No. 8761

Cooperation in Diverse Teams:

The Role of Temporary Group Membership

Christian Grund

Christine Harbring

Kirsten Thommes

January 2015 


\title{
Cooperation in Diverse Teams: The Role of Temporary Group Membership
}

\author{
Christian Grund \\ RWTH Aachen University \\ and IZA \\ Christine Harbring \\ RWTH Aachen University \\ and IZA \\ Kirsten Thommes \\ RWTH Aachen University
}

\author{
Discussion Paper No. 8761 \\ January 2015
}

IZA
P.O. Box 7240
53072 Bonn
Germany

Phone: +49-228-3894-0

Fax: +49-228-3894-180

E-mail: iza@iza.org

\begin{abstract}
Any opinions expressed here are those of the author(s) and not those of IZA. Research published in this series may include views on policy, but the institute itself takes no institutional policy positions. The IZA research network is committed to the IZA Guiding Principles of Research Integrity.

The Institute for the Study of Labor (IZA) in Bonn is a local and virtual international research center and a place of communication between science, politics and business. IZA is an independent nonprofit organization supported by Deutsche Post Foundation. The center is associated with the University of Bonn and offers a stimulating research environment through its international network, workshops and conferences, data service, project support, research visits and doctoral program. IZA engages in (i) original and internationally competitive research in all fields of labor economics, (ii) development of policy concepts, and (iii) dissemination of research results and concepts to the interested public.
\end{abstract}

IZA Discussion Papers often represent preliminary work and are circulated to encourage discussion. Citation of such a paper should account for its provisional character. A revised version may be available directly from the author. 


\section{ABSTRACT \\ Cooperation in Diverse Teams: The Role of Temporary Group Membership}

In organizations, some team members are assigned to a team for a predefined short period of time, e.g., as they have a temporary contract, while others are permanent members of the same team. In a laboratory experiment we analyze the cooperation levels resulting from diverse teams, where some team members remain with a team and others are switching teams. Our results reveal that teams consisting partly of members with temporary membership display a lower productivity compared to teams of permanent team members only. First, temporary team members cooperate less than permanent team members. Second, individual effort decisions increase with the number of team mates who are of the same type. This second effect holds for both temps and permanents. We argue that social identity is affected by team composition and the individuals' role in a team.

\section{JEL Classification: $\quad$ C9, M5}

Keywords: cooperation, economic experiment, public good, team

Corresponding author:

Christian Grund

RWTH Aachen University

Chair of Human Resource Management and Personnel Economics

Templergraben 64

D-52056 Aachen

Germany

E-mail: christian.grund@rwth-aachen.de 


\section{Cooperation in Diverse Teams: The Role of Temporary Group Membership}

\section{Introduction}

Modern organizations rely strongly on effective cooperation within teams of individual employees. In a nutshell, the strategic situation of cooperation within teams can be well captured by a social dilemma which is characterized by individuals whose self-interest is at odds with the group's interest, and which results in cooperation levels that are inefficiently low (e.g. Andreoni 1988). Due to the fundamental importance of cooperation in teams - or social dilemmas in general - there is a vast experimental literature on particular levers of cooperation in groups (e.g. Isaac et al. 1994, Kagel and Roth 1995, Fehr and Gächter 2000, Andreoni et al. 2003, Fischbacher and Gächter 2010, Dufwenberg et al. 2011, Böhm and Rockenbach 2013).

In organizational reality, individuals in a team are always diverse to some extent. While diversity of teams has been subject to several interesting recent studies and reviews (e.g. Cummings 2004; Boone and Hendriks 2009, Homan et al. 2008, Kavadias and Sommer 2009; Hoogendoorn et al. 2013; Niederle et al. 2013, see for a review Joshi and Roh 2009) one facet of diversity has been neglected so far. Teams in organizations are often composed of individuals of different durations of group membership. Some team members are permanent members and stay within a work team for an undefined or longer period of time; thus, there is some repeated interaction among team members. In contrast, other members are assigned to a team for a predefined short period and will only shortly interact with others. We refer to this dimension as diversity in team membership.

One pervasive and ongoing example for temporary group membership in organizations is the deployment of temporary employees. The share of temporary employees in the EU has remained constant at a high level of about $14 \%$ in the past 20 years and even in the US, the share is about $7 \%$ despite the labor-at-will clause in most US federal states (OECD 2014; Dertouzos and Karoly 1992). Firms may use temporary contracts as screening devices or due to labor cost or flexibility reasons (Kalleberg 2000). In general, all project teams including members who are supposed to contribute to the team only temporarily and members who are permanently part of the team are diverse teams with respect to group membership, e.g., project teams being shortly supported by experts (who may come from within the organization like a technical expert or from an external company like a consultancy). Moreover, job rotation has been implemented as a work practice in many firms and may result in teams in which some members do not necessarily repeatedly interact. 
Therefore, managers nowadays are often confronted with the challenge of composing teams of individuals who are temporary or permanent group members. Then, the question arises as to whether there are negative effects of temporary membership in teams. One may assume that individuals interacting only once in a social dilemma will cooperate less than individuals who repeatedly interact with the same subjects in a group, e.g., because direct reciprocity is more likely to evolve in a repeated partner situation. Our paper aims to provide a thorough analysis of the impact of temporary and permanent group membership on cooperation in a team setting. Particularly, we focus on team diversity by comparing teams consisting of different ratios of permanent to temporary members with homogeneous groups of permanent or temporary members only. To the best of our knowledge, there has been virtually no research undertaken on the performance of diverse teams consisting of permanent and temporary employees. This is true for both the experimental and the field data strand of the literature.

We deliberately address this question experimentally, as we can vary team diversity with respect to duration of group membership ceteris paribus in a controlled environment. In organizational reality, disentangling the effects of pure willingness to cooperate with other individuals from productivity efforts stemming from other motives, e.g. a temporary employees hoping for an unlimited contract, is hardly feasible. Here, we may focus on the pure cooperation effect in settings where only the length of group membership, i.e., the frequency of interaction, is varied. We conduct a laboratory experiment and model a team situation by implementing the classic public good game according to Fehr and Gächter (2000).

Our main results are the following: We confirm the findings of Fehr and Gächter (2000) by showing that cooperation within teams consisting of permanent employees only is higher than in groups of temporary agents only. The contribution of temporary employees is also lower than that of permanent employees in diverse teams consisting of both temporary and permanent agents. Cooperation increases with the number of team members who are of the same type. Interestingly, a large portion of individuals who show an initial tendency to cooperate in a pre-test act like freeriders when assigned to a temporary position within a diverse team. This is particularly true, when the agent is the only one with a temporary team member.

The remainder of our contribution is organized as follows: We give a short overview of the related literature in in section 2, and we present the experimental design and procedure of our treatments in section 3. Results are presented in section 4 . Section 5 concludes.

\section{Related Literature}

Gaining a better understanding of the effects of team membership diversity is essential as diversity in temporal group membership is common practice but not fully comprehended yet. This is true for both the 
experimental and the field data strand of the literature. While there are findings from economic experiments on other diversity dimensions, such as heterogeneity in endowments (e.g. Chan et al. 1999, Cherry et al. 2005), returns (Montmarquette et al. 2004, Fischbacher et al. 2012), or player behavior in pre-tests (e.g. Burlando and Guala 2005; Fischbacher and Gächter 2006) are relatively well understood, diversity in terms of the duration of the employment contract has not yet been researched. Economic experiments on the duration of team membership has so far been limited to comparisons between teams consisting of either all temporary or all permanent members (stranger and partner setting, respectively) and have shown rather mixed results: While some researchers (e.g. Croson 1996, Sonnemans et al. 1999, Fehr and Gächter 2000, Keser and Van Winden 2000) do find that contributions in partner settings are significantly higher than those in stranger settings, other researchers encounter divergent results. In some experiments, stranger groups cooperated more than partner groups did (e.g. Andreoni 1988, Palfrey and Prisbrey 1996); contributions in both settings were almost equally high (Weimann 1994) or seemed to depend on the location and regional characteristics (Burlando and Hey 1997, Brandts et al. 2004). With respect to diversity in contracts, some experimental researchers analyze gift-exchange experiments between agents and principals if the agents are heterogeneous (e.g. Ohana 2011, Angelova et al. 2012): In their settings, agents do not have to cooperate with each other, but the exchange relation with the principal is analyzed. Angelova et al. (2012) find that principals discriminiate between agents with longand short-term contracts by offering higher wages to the long-term agents and short-term employees react to that discrimination by choosing lower effort levels. We are not aware of any experimental research on the intra-team dynamics of diversity in team membership.

The same observation holds true for applications such as temporary employment, job rotation or project teams. Field data with respect to temporary employment has been analyzed on every level but the team level: On an economy level, temporary work is sometimes presented as a way of increasing labor market flexibility (Bentolila and Bertola 1990, Bentolila and Saint Paul 1994, and Booth 1997), while other researchers suspect temporary jobs of increasing overall unemployment in an economy (Alonso-Borrego et al. 2004). With respect to firm-performance, findings are also conflicting: One the one hand, researchers find that temporary jobs are less costly than lay-offs (Goux et al. 2001) and increase innovativeness of a firm (Arvanitis 2005). On the other hand, other researchers find a negative relation between temporary work and overall firm performance (Boeri and Garibaldi 2007, Michie and SheehanQuinn 2001). On the individual level, research shows that temporary jobs can serve as a stepping stone towards regular employment (Heinrich et al. 2005). However, other research stresses that temporary employees have to bear negative consequences, such as lower wages, less training, and a greater likelihood of unemployment (De Cuyper et al. 2008, Gagliarducci 2005, de la Rica 2004, Booth and Francesconi 2002). 
The missing link between the layers of individual, firm, and economy levels until now has been that of the team level. This observation holds not only true for temporary employment, but also for job rotation: While individual and organizational outcomes of job rotation are subject to recent research (e.g. Ortega 2001, Eriksson and Ortega 2006), there is no research on the team level outcomes to the best of our knowledge. With respect to temporary project teams, most research focuses on the team level, but diversity in team membership is not taken into account, i.e. all agents are assumend to be temporary or permanent within a project team (e.g. Saunders and Ahuja 2006, Bakker 2010).

Although past research recognizes that the co-employment of temporary and permanent agents in one team affects not only the temporary but also the permanent agents' satisfaction (e.g. Wuchty et al. 2007, Bartel et al. 2007, Bloom and van Reenen 2007), the productivity effects of team diversity in terms of varying temporal group membership have not been systematically analyzed yet. A lack of evidence from field data may have been caused by the fact that decisions about team formation in firms are highly endogenous, so that clear causal effects for cooperation or productivity cannot be derived. We address this problem with our experimental design by trying exogenious team formation of temporary and permanent team members.

\section{Experimental Design and Procedure}

Our paper tests the effects on cooperation of team composition with regard to variations in the number of permanent and temporary employees. We aim to explore the effects of diverse teams on cooperation and their causes by conducting adapted versions of the public good game of Fehr and Gächter (2000). In this experimental design, subjects form teams consisting of four players each. We model the team situation as a classical social dilemma game, i.e., a public good problem. Each subject has to individually decide how much of her 20 ECU endowment she wants to invest into the public good project and how much she wants to put aside into her private account. Investments into the public good project are multiplied by 1.6, and the resulting amount is equally re-distributed to each of the four subjects in the team, so that the marginal per capita return is 0.4. Savings to the private account remain stable in value and are paid out only to the subject to whom the private account belongs. In such a setting, the degree of cooperation in a team directly determines its productivity. In the initial paper, Fehr and Gächter (2000) compare the contributions to the public good of randomly matched and re-matched groups (stranger-design) to the contributions of stable teams, which remain constant in composition over time (partner-design). However, to the best of our knowledge, this game has never been applied to mixed teams with regard to varying temporal group membership before. 
In the permanent employees' setting (PPPP), all team members work together during the 10 rounds of the experiment (partner-design). In the temporary employees setting (TTTT), all individuals are re-allocated to new group members after each round (stranger-design). We further introduce two treatments with blended teams: In one setting, one team member is re-allocated randomly to a new group after each round, while three team members remain together in a group (РPPT). In the other setting, two team members switch to other teams after each round, while the other two team members remain permanently in the team (PPTT). Participants are informed about their type of group membership before the experiments started.

In order to understand how different behaviouralal types of players behave in our experiment, we asked participants to make decisions in an additional public good game before our actual experiment started In this task, each individual was randomly assigned to a group and was asked to make a one-shot public good decision, as described above. Each individual had to make different sets of decisions: an unconditional and a conditional one. The unconditional decision meant making a contribution to the public good without conditioning it to others' decisions. In the conditional decision, individuals were asked about their contributions conditional to the mean of the other three players' contribution. All possible integer mean contributions from 0 to 20 were given to each individual. We refer to this first set of decisions before our main experiment as the pre-test in this contribution. Using the "strategy-method" (Selten 1967) allows us to reveal different behavioural types of individuals, such as freeriders (who contribute nothing independently of the mean contribution of their team mates) and conditional cooperaters (who contribute a positive amount which increases in dependence of the other team mates' average contributions, e.g. Fischbacher et al. 2001, Kocher et al. 2007).

All sessions took place between October 2013 and July 2014 at the AIXperiments laboratory located in RWTH Aachen University, Germany. Subjects were students at RWTH Aachen, who had been recruited with “ORSEE” (Greiner 2004). The experiments were programmed with "z-Tree” (Fischbacher 2007). Each subject participated in only one of the treatments. Subjects were randomly assigned to teams and also randomly assigned to be either a permanent or a temporary team member (where applicable). Permanent members remained with the team for the whole experiment, whereas temporary ones switched teams after each round. They all received written instructions, and some test-questions had to be answered correctly before the experiment could start ${ }^{1}$. Before any decision was made, participants were informed about their type for the first ten rounds (permanent or temporary) and also their group composition (PPPP, PPPT, PРTT or TTTT). It was not possible for team members to communicate with each other. ${ }^{2}$ After

\footnotetext{
${ }^{1}$ See APPENDIX B for translated instructions (the original instructions were given in German).

${ }^{2}$ See Brosig (2002) and Brosig et al. (2003) for the impact of communication on cooperation in public good games.
} 
each round, all participants were informed of their private income resulting from the transfers to their private account as well as from the pay-off from the public good project. Additionally to the experimental design described above, all participants were asked for their beliefs about each of their team members' contributions in each round. This guess was incentivized, e.g. correct guesses were rewarded with a small amount of money. The instructions provided information on all ten rounds of the experiment.

In total, 336 students from various disciplines participated in the experiment and made their decision about the public good contribution in 10 consecutive rounds. 112 participants were assigned to the PPPP treatment, 112 participants were assigned to the PPPT treatment. 56 individuals participated in the PPTT and the TTTT treatments respectively. ${ }^{3}$ We are therefore able to examine 3,360 individual decisions and as many beliefs about others' contributions. One session lasted for about 1.5 hours, and subjects earned about 12.64 Euros on average based on their own and their group members' decisions in addition to a show-up fee of 3 Euros. To avoid wealth effects, one round was randomly chosen to be relevant for the pay-off. Subjects were paid anonymously after the experiment.

\section{Findings}

\subsection{Cooperation across treatments}

In order to assess the effects on cooperation of temporary employees in a team, we compare the contributions in teams of permanent team members only (PPPP) with those of teams that included one temporary team member (PPPT), or two temporary team members (PPTT), or consisting of temporary members only (TTTT) in a between-subjects design. Figure 1 illustrates the development of mean individual contributions of team members by treatment and round, revealing that contributions decrease evenly across treatments. Also, teams with at least one temporary agent contribute on average less over the whole ten rounds.

\footnotetext{
${ }^{3}$ The whole experiment consisted out of two more tasks which were conducted after this experiment and cause the unequal number of participants in the treatments. The additional tasks were conducted to answer an only loosely related research question on changes in team formation. As the additional tasks were conducted after the experimental parts we rely on in this paper, interference from the additional tasks is impossible as instructions about the later tasks were given after the ten rounds of the experiment analyzed here.
} 


\section{Figure 1: Mean contribution over rounds in homogeneous and heterogeneous teams}

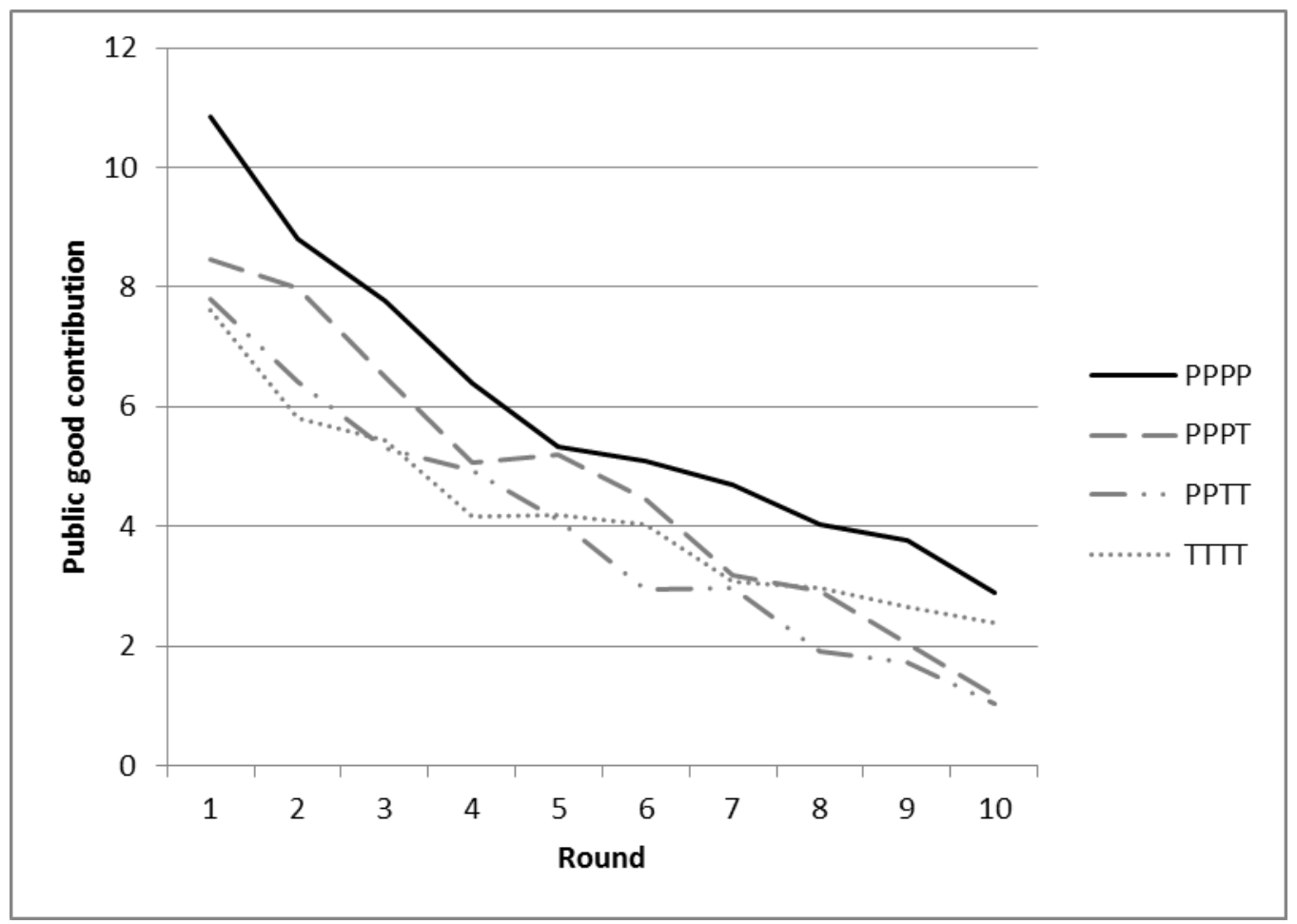

Individuals cooperating in teams consisting of four permanent agents contribute 5.96 on average to the common project, while individuals in PPPT contribute significantly less (mean contribution: 4.68, $\mathrm{p}<0.001) .{ }^{4}$ In the PPTT treatment, individuals contribute 3.97 on average, which is even less than those in PPPT ( $\mathrm{p}=0.072)$. Individuals in the TTTT treatment contribute significantly less (mean contribution: 4.23, $\mathrm{p}<0.001$ ) than in the PPPP treatment. However, contributions in TTTT do not differ significantly from those in the PPPT treatment $(\mathrm{p}=0.234)$ and in the PPTT treatment $(\mathrm{p}=0.533)$. Thus, contributions are clearly highest in teams consisting of permanent members only.

\subsection{Contributions and beliefs of players by type of group membership and team composition}

Treatment differences in contributions can be due to lower contributions of permanent and/or temporary members. We approach this question by comparing the contributions of different types of players in the homogeneous treatments (PPPP, TTTT) with the efforts provided in diverse teams (PPPT, PPTT).

\footnotetext{
${ }^{4}$ If not stated differently, the Mann Whitney U-test is used for all treatment differences (two-tailed) while the Wilcoxon Signed rank test (also two-tailed) is applied to check for significant differences within the treatments.
} 
Across all treatments, we observe that temporary team members contribute in general less to the public good than their permanent counterparts do (mean of $\mathrm{P}=5.54$, mean of $\mathrm{T}=3.67, \mathrm{p}<0.001$ ). This difference in contribution between types is firstly caused by treatment effect, (PPPP vs. TTTT) as mentioned above. Secondly, it is caused by intra-treatment differences between types of group membership in PPPT $(\mathrm{p}<0.001)$ and PPTT $(\mathrm{p}=0.065)$.

Figure 2 displays the mean contributions over rounds for each treatment and type of group membership ( $\mathrm{T}$ = temporary, $\mathrm{P}$ = permanent team member):

\section{Figure 2: Mean contribution by team composition and type of group membership}

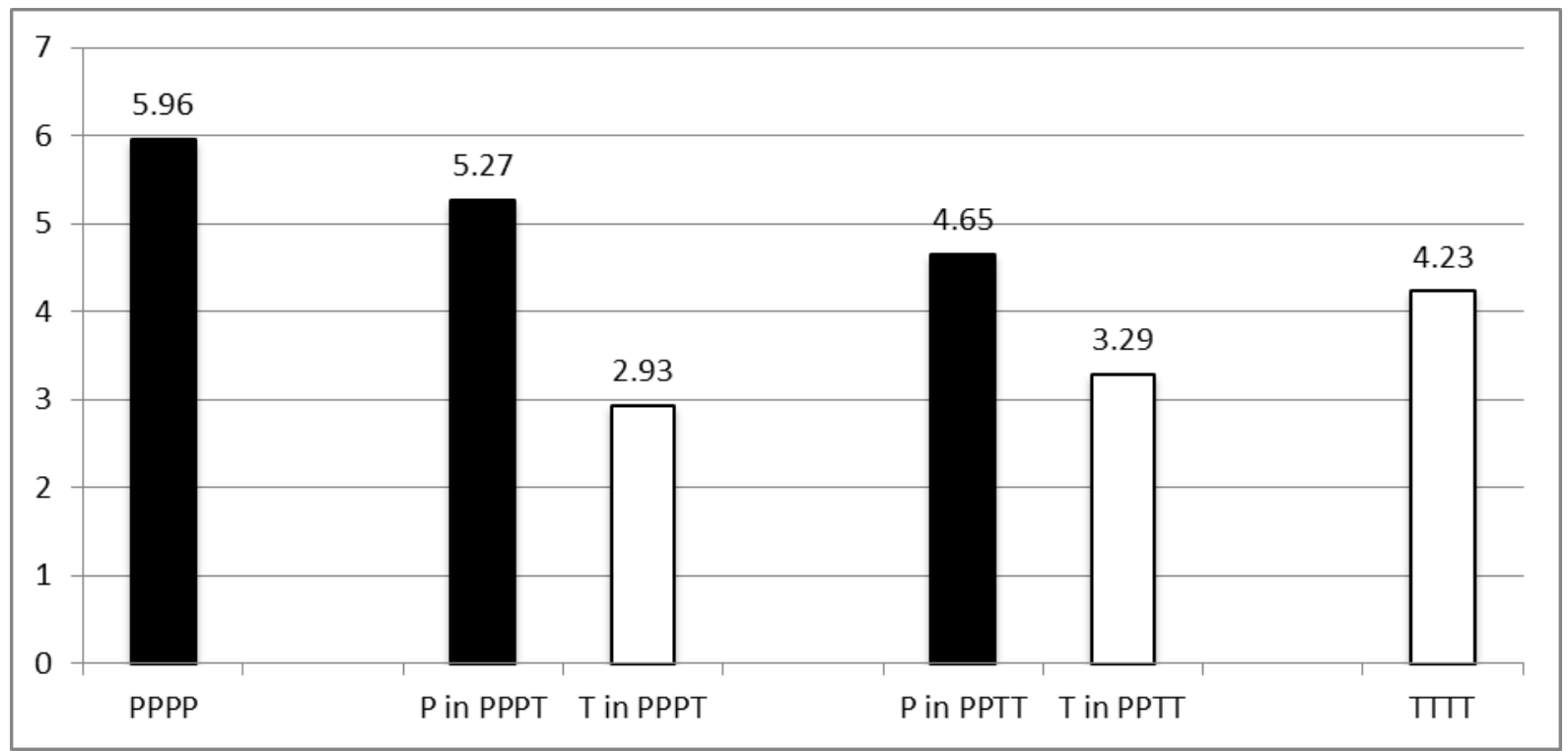

Compared to employees in PPPP (mean=5.96), permanent agents contribute less in PPPT (mean $=5.27$ ) and PPTT (mean $=4.65$ ). Differences from PPPP are weakly significant (Mann Whitney-U test, $\mathrm{p}=0.067$ and $\mathrm{p}=0.084$ respectively).

Besides, we observe that temporary team members in PPPT contribute significantly less (mean=2.93,) than temporary team members in PPTT (mean=3.29, p=0.030). Temporary agents in homogeneous TTTT groups contribute most (mean=4.23) and significantly more than temporary agents in PPPT $(\mathrm{p}<0.001)$ and temporary agents in PPTT $(\mathrm{p}=0.058$ ). Thus, we observe that in diverse teams, both temporary and permanent agents contribute significantly less than participants with the same type of group membership, but as part of a homogeneous group consisting of permanent or temporary agents only. 
We also elicit beliefs regarding each team members' decisions. These beliefs may shed some light on the motives of different types of players. Figure 3 shows averages of differences in beliefs and contributions: On average, individuals in all group compositions significantly overestimate the contributions of their fellow team mates ( $<<0.001$ in each case). In PPPT, permanent agents expect other permanent agents to contribute significantly more than temporary agents $(\mathrm{p}<0.001)$. In PPTT, both permanent and temporary agents expect permanent agents to contribute more to the public good than temporary agents $(\mathrm{p}<0.001$ in both cases).

\section{Figure 3: Mean beliefs and contributions}

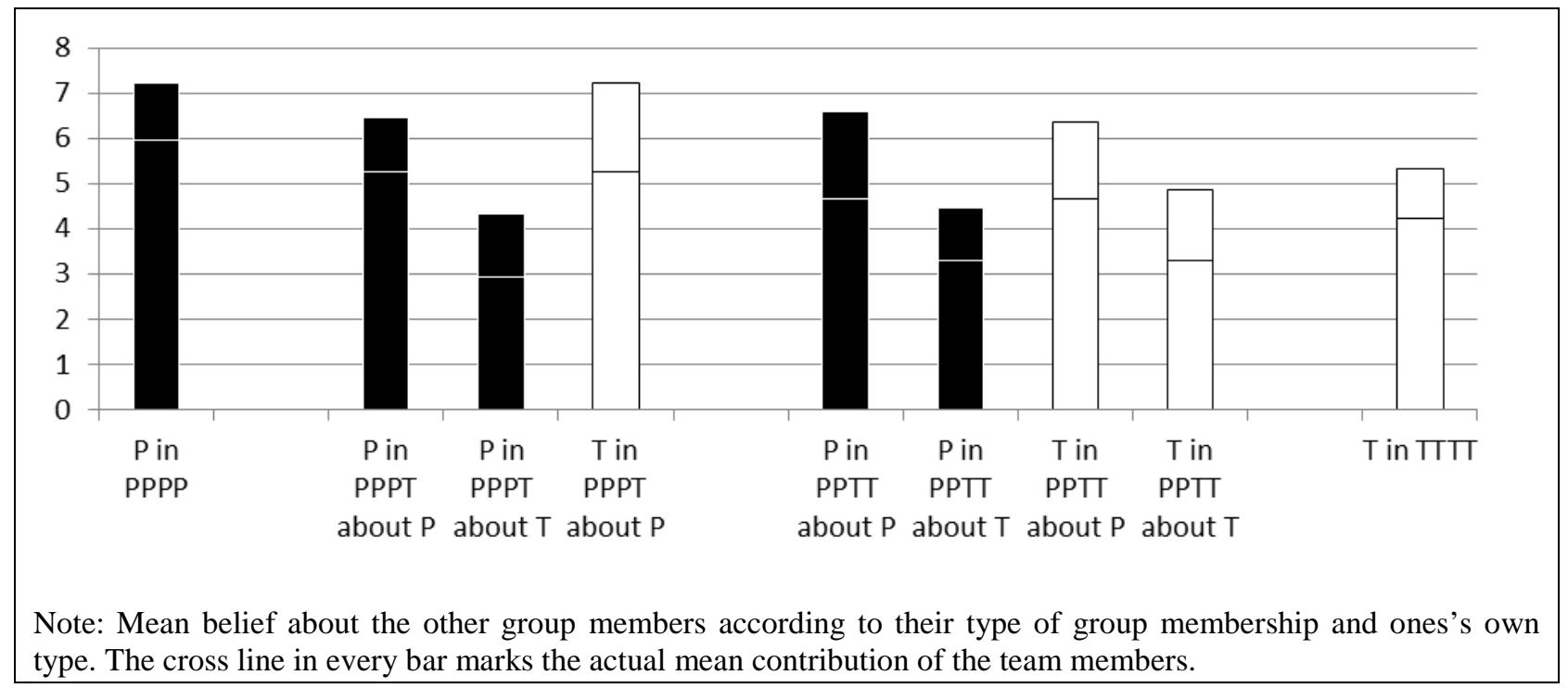

Comparing beliefs across treatments reveals that permanent agents in PPPP expect their team members to contribute significantly more than permanent team members in PPPT and PPTT expect from other permanent team members in their team ( $p=0.003$ and $p=0.038$, respectively). In diverse groups, the expectations from permanent agents towards other permanent agents do not differ significantly from each other $(\mathrm{p}=0.853)$ and neither does the expectation of permanent agents towards temporary agents in blended teams $(\mathrm{p}=0.492)$.

Temporary agents expect higher contributions from other temporary agents in groups consisting of temporary agents only than in groups with two permanent agents $(\mathrm{p}=0.025)$. Further, temporary agents expect higher contributions from permanent agents in PPPT than from permanent agents in PPTT $(\mathrm{p}=$ $0.044)$. 
In sum, differences in individual contributions seem to be in line with differences in beliefs regarding team members' contributions.

\subsection{Predisposition for cooperation and multivariate analysis}

In order to examine the various possible determinants of contributions together in a multivariate analysis, we apply tobit estimations and cluster at the team level. Table 1 shows the results of the analysis of individual contributions in the ten rounds of the experiment. We start by exploring differences in contributions by type of players (temps versus permanents) and the number of team mates that are of the same type as oneself (values from 0 to 3$)^{5}$. Controlling for the time effects (round 1 to 10), we confirm that temps contribute significantly less than permanent team members. Besides we find, also in line with our non-parametric results, that contributions increase in the number of team mates of the same type as oneself (see model I).

The further models, as depicted by Table 1, act as robustness checks. Differences in contributions across treatments and types may also be caused by differences in individuals’ predisposition to cooperate. As mentioned above we asked subjects for their conditional contributions in a one-shot public good game using the strategy method before our main experiment started. Accordingly, we have $n=21$ decisions of each subject, given the mean contribution of their group members from 0 to 20. We calculate Spearman rank correlations for each individual between the own contribution and the given contributions of others as a measure for a disposition of the conditional willingness to cooperate. We recode insignificant correlations to zero. Average values of this measure vary (not significantly) from 0.530 to 0.667 across contract types and team compositions in our experiment. This measure is added in model II, and we find a positive relation to contributions in our experiment. Moreover, we analyze whether the conditional willingness to cooperate, which can also be interpreted as a measure for the degree of reciprocity (Fischbacher et al. 2001) is differently related to contributions across behavioral types. We therefore construct an interaction term with Temp and find that the positive relationship is particularly relevant for temps and insignificant for permanents (see model III). The results concerning type and the number of team mates who have the same type of contract as oneself are not affected by these additional controls. ${ }^{6}$

\footnotetext{
${ }^{5}$ Implementing the number of team mates that are of the same type as oneself as dummy variables in the estimation lead to the same qualitative results. See APPENDIX A. 1.

${ }^{6}$ We also use the decisions made in the pretest in an alternative way by defining certain types of players. According to Rustagi et al. (2010), we distinguish between freeriders (contributing a mean of equal to or below 1 in the 21 decisions), weak cooperators ( increasing contributions, but not on the diagonal), strong cooperators (increasing and on the diagonal) and others. Using these categories instead of the conditional willingness to cooperate leads to similar results. See APPENDIX A.2 for the results.
} 
Table 1: Tobit regressions on individual contributions

\begin{tabular}{|c|c|c|c|c|c|c|}
\hline & $\mathbf{I}$ & II & III & IV & $\mathbf{V}$ & VI \\
\hline Temp (1=yes) & $\begin{array}{l}-2.664 * * * \\
(0.975)\end{array}$ & $\begin{array}{l}-2.696 * * * \\
(0.970)\end{array}$ & $\begin{array}{l}-5.132 * * * \\
(1.697)\end{array}$ & $\begin{array}{l}-4.167^{* * *} \\
(1.153)\end{array}$ & $\begin{array}{l}-2.951^{* *} \\
(1.112)\end{array}$ & $\begin{array}{l}-3.113^{* * *} \\
(1.105)\end{array}$ \\
\hline $\begin{array}{l}\text { \# of team mates with the } \\
\text { same type of group } \\
\text { membership }\end{array}$ & $\begin{array}{l}1.342 * * * \\
(0.491)\end{array}$ & $\begin{array}{l}1.201 * * \\
(0.472)\end{array}$ & $\begin{array}{l}1.155^{* *} \\
(0.478)\end{array}$ & $\begin{array}{l}0.854 * * * \\
(0.269)\end{array}$ & $\begin{array}{l}0.552 * * \\
(0.250)\end{array}$ & $\begin{array}{l}0.676 * * * \\
(0.260)\end{array}$ \\
\hline $\begin{array}{l}\text { Conditional willingness to } \\
\text { cooperate }\end{array}$ & & $\begin{array}{l}3.605^{* * *} \\
(1.195)\end{array}$ & $\begin{array}{l}2.471 \\
(1.658)\end{array}$ & $\begin{array}{l}1.346 \\
(1.062)\end{array}$ & $\begin{array}{l}0.857 \\
(1.063)\end{array}$ & $\begin{array}{l}0.999 \\
(1.052)\end{array}$ \\
\hline $\begin{array}{l}\text { Conditional cooperation * } \\
\text { Temp }\end{array}$ & & & $\begin{array}{l}3.611^{*} \\
(1.939)\end{array}$ & $\begin{array}{l}3.685^{* * *} \\
(1.402)\end{array}$ & $\begin{array}{l}3.477 * * \\
(1.383)\end{array}$ & $\begin{array}{l}3.324 * * \\
(1.364)\end{array}$ \\
\hline $\begin{array}{l}\text { Belief about team mates } \\
\text { contribution }\end{array}$ & & & & $\begin{array}{l}1.418^{* * *} \\
(0.069)\end{array}$ & & $\begin{array}{l}0.967 * * * \\
(0.082)\end{array}$ \\
\hline $\begin{array}{l}\text { Team mates' contr. precedent } \\
\text { round }\end{array}$ & & & & & $\begin{array}{l}1.431 * * * \\
(0.076)\end{array}$ & $\begin{array}{l}0.603 * * * \\
(0.097)\end{array}$ \\
\hline Round & $\begin{array}{l}-1.465^{* * *} \\
(0.120)\end{array}$ & $\begin{array}{l}-1.457^{* * *} \\
(0.119)\end{array}$ & $\begin{array}{l}-1.458^{* * *} \\
(0.119)\end{array}$ & $\begin{array}{l}-0.378^{* * *} \\
(0.073)\end{array}$ & $\begin{array}{l}-0.169 * * \\
(0.080)\end{array}$ & $\begin{array}{l}-0.116 \\
(0.074)\end{array}$ \\
\hline Constant & $\begin{array}{l}7.100 * * * \\
(1.330)\end{array}$ & $\begin{array}{l}5.038 * * * \\
(1.635)\end{array}$ & $\begin{array}{l}5.931 * * * \\
(1.884)\end{array}$ & $\begin{array}{l}-7.244^{* * *} \\
(1.395)\end{array}$ & $\begin{array}{l}-7.161^{* * *} \\
(1.244)\end{array}$ & $\begin{array}{l}-8.977 * * * \\
(1.272)\end{array}$ \\
\hline Observations & 3,360 & 3,360 & 3,360 & 3,360 & 3,024 & 3,024 \\
\hline Pseudo R² & 0.030 & 0.034 & 0.035 & 0.119 & 0.094 & 0.115 \\
\hline
\end{tabular}

Model IV integrates the beliefs regarding others' contributions into the analysis. We find a highly significant and large effect on contribution. Subjects even react with an increase in the amount of 1.4 with a one point increase of the belief. Moreover, subjects experience different levels of cooperation during the 
experiment. We implement team members' contributions in previous rounds instead of beliefs in model V. Doing this, we examine rounds 2 to 10 only. Subjects who experienced cooperation in the past, react with higher own contributions. Team members' contributions in the precedent round are highly correlated with beliefs in the current round (rho=0.82, $\mathrm{p}<0.001$ ). This is even the case for temps who change teams over rounds (rho=0.77, $\mathrm{p}<0.001$ ). Estimating a joint model $(\mathrm{VI})$ with both variables reveals that both beliefs and experiences in the precedent round are significantly related to own contributions in the current round. Again the results with respect to types and the number of team mates who have the same type of contract as oneself are robust to these modifications.

The significant interaction term between the type and the conditional willingness to cooperate suggests that the allocation to specific roles and team compositions differently encourages individuals to act according to their stated predisposition. We therefore analyze in the following whether individuals in the different settings behave according to their initial tendency to cooperate: If individuals are perfectly able to behave according to their stated predisposition, their contribution in a certain round should depend on their belief and should be in line with the specified decision in the pre-test.

In most cases, individuals contribute - given a particular belief - at least the amount they had stated in the pre-test or above on average (see Figure 4). Positive deviations, i.e., positive differences between actual contribution and stated contribution in the pre-test, may be due to the different settings: While the decisions in the pre-test were elicited in a one-shot situation, real contribution decisions are made in the context of a repeated game over the course of 10 rounds. Particularly, individuals who are assigned a permanent contract in the experiment tend to contribute more than in the pre-test, which is not surprising, as behavior in a repeated setting typically results in higher cooperation levels. However, there are also no considerable differences between homogeneous teams with either only temporary or only permanent members, which may be due to some indirect reciprocity in TTTT.

Most interestingly, we find negative deviations from the decisions in the pre-test for temps in diverse teams, in particular in PPPT with only one temp. In contrast, permanent team members in blended teams show remarkably positive deviations. Within treatment, differences are significant for both PPPT $(\mathrm{p}<0.001)$ and PPTT $(\mathrm{p}=0.040)$. 
Figure 4: Mean difference between actual contribution and stated contribution in a one shot public good game (pre-test)

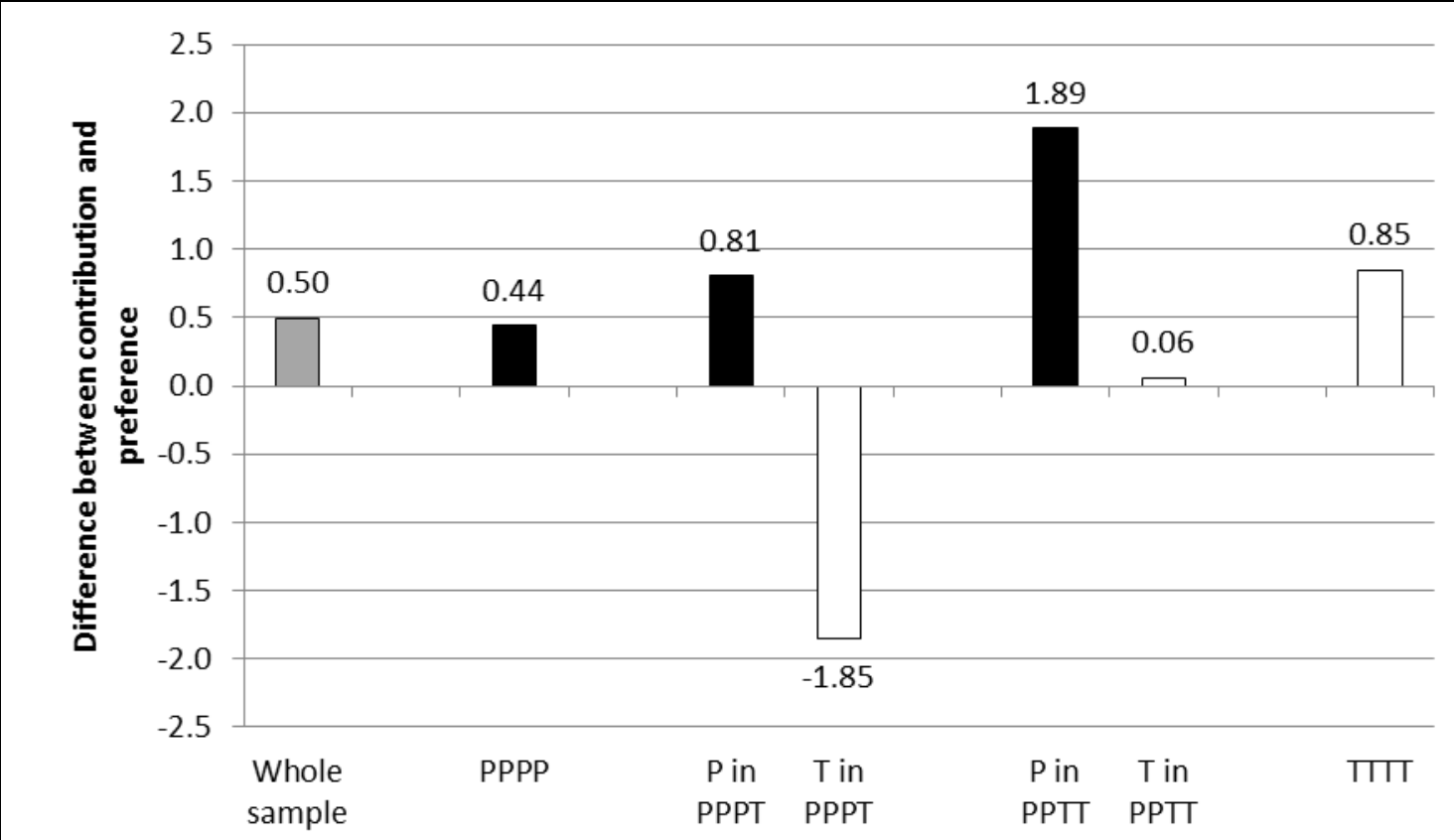

Note: Difference between contribution in the experimental setting and stated contribution in a strategic one-shot public good game for a the stated belief.

Our results suggest that individuals react differently to being assigned a particular role in a specific team. Not very surprisingly, permanent agents in homogeneous groups in general contribute more in the situation of a repeated game than they stated in a strategic one-shot situation. However, also temps in teams consisting of temps only contribute more than stated in a strategic one-shot situation and deviate more than permanent agents in homogeneous groups $(\mathrm{p}<0.001)$.

In diverse teams, the share of temps and permanent members matters: The fewer permanent agents there are in a group, the more they exceed over their prior contribution choice for the benefit of the group; the difference between P in PPTT and P in PPPT is significant $(\mathrm{p}<0.001)$ as well as the difference between P in PPTT against $\mathrm{P}$ in PPPP $(\mathrm{p}<0.001)$. The opposite tendency is true for temps: The fewer temporary agents there are in a group, the more they deviate from their prior contribution choice to the detriment of the group, the differences between $\mathrm{T}$ in PPPT and T in PPTT is significant $(\mathrm{p}<0.001)$ as well as the difference between T in PPTT and T in TTTT $(\mathrm{p}<0.001)$.

When we have a closer look at individual data, we observe two kinds of remarkable and extreme behavioral deviations from decisions in the pre-test: (1) Individuals who act like freeriders in the pre-test, but show positive contributions when they interact repeatedly. (2) In contrast, some individuals reveal 
themselves to be conditional contributors in the pre-test, but - surprisingly - act like freeriders, denoted as “dropouts”, during the experiment. Freeriders are defined as contributing a mean of equal to or below 1 in the 21 decisions of the pre-test. The share of freeriders slightly varies across treatments from 0.143 to 0.214. Figure 5 shows the frequencies of acting in contrast to own behaviour in the pre-test.

Figure 5: Proportion of individuals acting in contrast to the initial tendency to cooperate shown in the pre-test

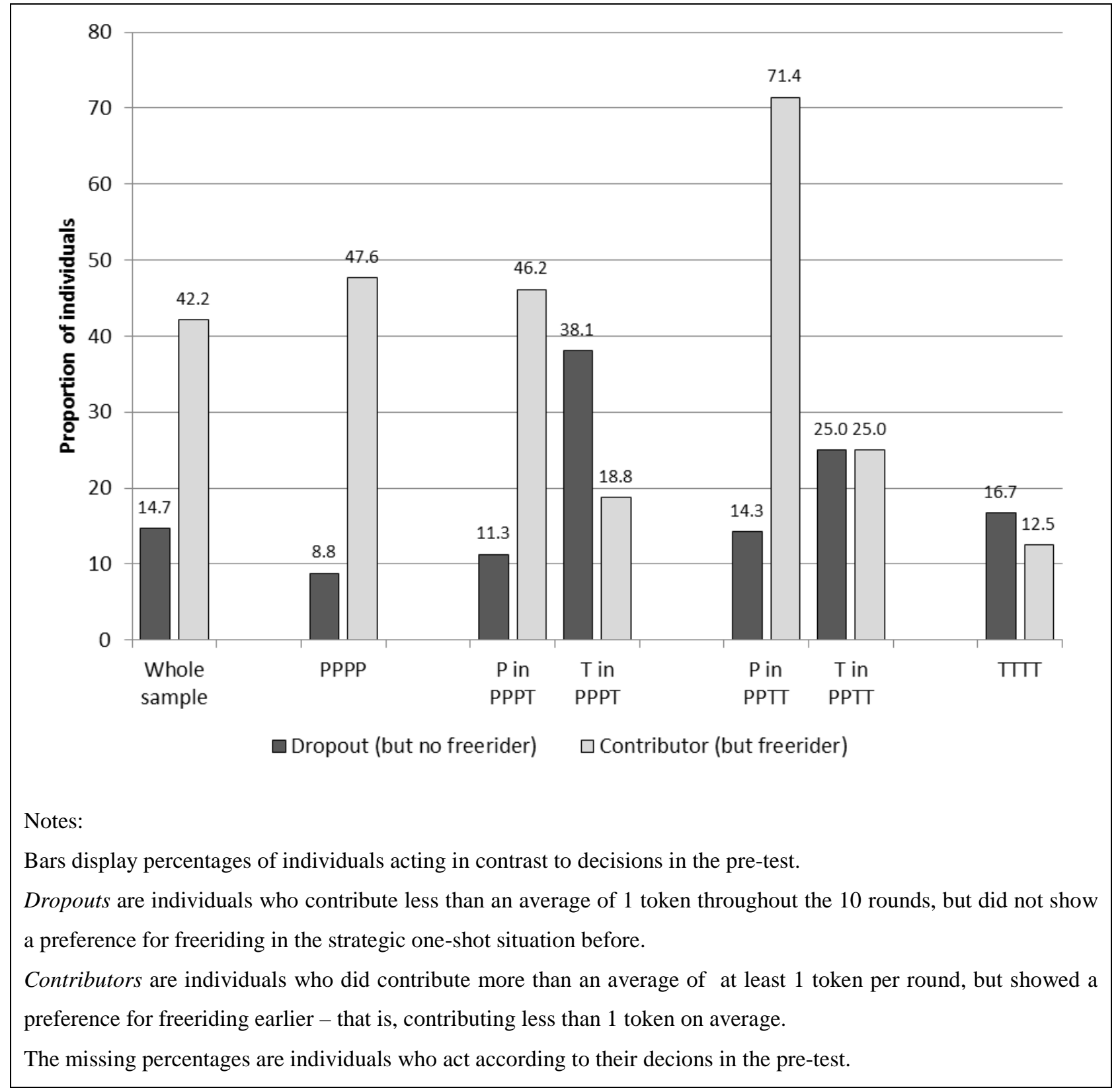

Out of the individuals who contributed in the pre-test, 0.147 of them drop out of the game in the course of the actual experiment and do not contribute more than 1 token per round. The share of these dropouts, 
however, varies systematically and significantly over types of group membership and team composition (Fisher's exact test, $\mathrm{p}=0.048$ ). In particular, individuals assigned to the role of a temporary team member in the PPPT treatment are more likely to contribute less than 1 token per round (although they have not acted like freerider in the pre-test) compared to permanent team members who contributed at least one token in the pre-test (Fisher's exact test, $\mathrm{p}=0.011$ ).

In diverse teams, temporary team members are more likely to drop out than their permanent team mates are (in PPPT: Fisher's exact test $\mathrm{p}<0.001$ in PPTT: Fisher's exact test $\mathrm{p}=0.040$ ). Temporary team members are also more likely to drop out in PPPT than temporary team members in TTTT are (Fisher's exact test $\mathrm{p}=0.029$ ); the difference between temporary team members in PPTT and TTTT is not significant (Fisher's exact test $\mathrm{p}=0.156)^{7}$

Remarkably, the high share of dropouts of temps in PPPT is neither in line with the behavior revealed in the pre-test nor in line with altered beliefs of temps in comparison with other agents. When we compare the beliefs and contributions of temps who have not revealed themselves as freerider in the pre-test, we see stark differences in contributions, but not in beliefs. Figure 6 exhibits beliefs and contributions of these temporary agents:

\footnotetext{
${ }^{7}$ We also observe that a significant share of individuals contribute more than an average of 1 token per round, although they have announced a general preference for freeriding before. Out of all 64 freeriders (out of 336 individuals in total), 0.42 contributed to the public good. Again, the fraction of contributors against their preferences varies according to their assigned membership type: Temporary team members are significantly less likely to act against their freerider preferences (Fisher's exact test, $\mathrm{p}=0.006$ ). We observe also a deviation towards contributing within the group of permanent agents: Permanent agents in the PPTT treatment are more likely to act against their freeriding-preferences (Fisher's exact test, $\mathrm{p}=0.065$ ) compared to other permanent agents and compared to their temporary team mates (Fisher's exact, $\mathrm{p}=0.099$ ).
} 


\section{Figure 6: Beliefs and contributions of temps in PPPT (non-freeriders based on the pre-test only) ${ }^{8}$}

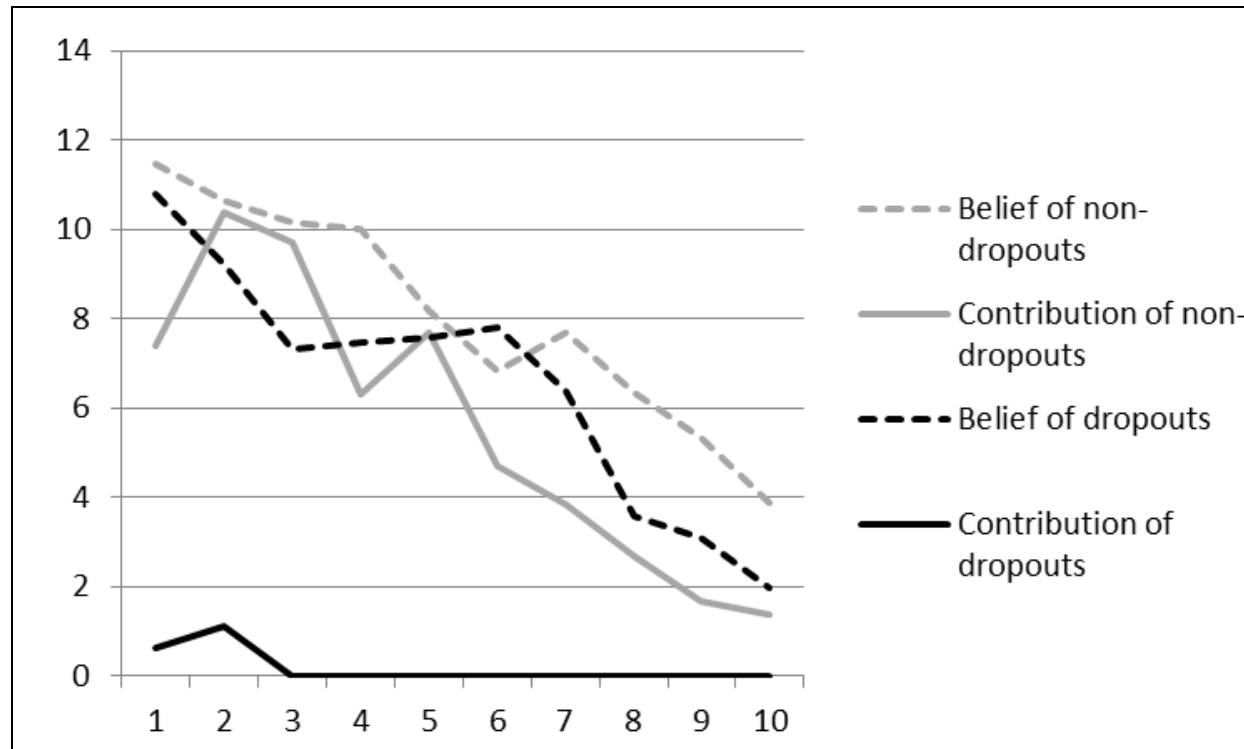

Notes:

Dropouts are individuals who contribute less than an average of 1 token throughout the 10 rounds, but did not show a preference for freeriding in the strategic one-shot situation before.

Freerider are individuals who revealed a preference for free-riding in the pre-test.

The 38\% of individuals who drop out when assigned a role of temporary member in PPPT therefore have roughly the same beliefs about their team members as other temporary agents, and have no personal preference for freeriding. Only their being assigned to a certain role and group composition triggers them to drop out of the cooperation.

\section{Discussion and Conclusion}

We experimentally investigate the impact of team composition with respect to individual duration group membership on cooperation by conducting a public good game in the laboratory. First, we confirm earlier results by Fehr and Gächter (2000) that there is more cooperation within teams of permanent members than within teams consisting of only temporary members switching groups in each round. Second, we reveal that temporary team members also contribute less than the permanent team mates in diverse teams.

\footnotetext{
${ }^{8}$ We have 28 individuals in the role of a temp in PPPT, 7 are categorized as freerider in the pre-test and are therefore excluded from this graph as we are interested in the behaviour of individuals who are generally willing to cooperate here.
} 
Third, contributions increase with the number of group members being ot the same type. This holds true for both temporary and permanent team members.

Some of our results could be interpreted with the help of social identity theory going back to Tajfel and Turner (1979). The type of group membership may well serve as a means to categorize participants in two groups. In homogenious groups, where all team members are either permanently or temporarily assigned to the group, participants might perceive themselves as members of the same "social category". Thus, they may develop a weak form of identity which may induce them to cooperate (see also Akerlof and Kranton 2000, Eckel and Grossmann 2005, Chen and Li 2009 and also Goette et al. 2006, Charness et al. 2007). Moreover, in PPPP direct reciprocity may additionally enhance cooperation which is the case wherever at least two participants with permanent contracts interact with each other. In diverse teams, however, participants may be in a conflict between an increased tendency to cooperate with in-group members and a lower tendency to cooperate with members perceived as out-group. Thus, in groups of three permanent members, group identity only evolves among permanent members with the only temp being an out-group participant who in fact contributes much less. In groups of two permanent and two temporary agents, two sub-groups are created; both being confronted with cooperation decisions towards one in-group member and two out-group participants. Consequently, cooperation levels of permanent team members are somewhat lower in groups with only one in-group member than in groups with two ingroup members. Alike, temporary group members cooperate more, the more similar group members are in their team.

Interestingly, a surprisingly large share of individuals who have an initial tendency to conditionally cooperate act like freeriders once they are allocated to being a temporary member in a diverse team. This is particularly the case if there is only one temporary agent in a team. Our results reveal that a large share of individuals drop out of the cooperation when assigned the role of a temporary member in a team. This is in line with our interpretation above in the light of social identity theory. Like Fischbacher and Gächter (2010), we see for this subset of individuals that it is not beliefs that are driving behavior. Particularly, temporary agents confronted with three permanent group memebers may feel like out-group participants belonging to another (inferior) category and may, thus, resign from cooperation although they have relatively high beliefs about the contributions of others.

Our results imply that the perception of the temporal horizon of group membership may induce participants to identify with other group members and can create sub-groups within one team. Still, the composition of a team regarding its diversity with respect to group membership is crucial for cooperation. Temporary agents contribute least if there is no team mate of the same type: They might perceive themselves as being the only one in an (unfavorable) outsider position compared to other team members. 
Even many of those individuals who initially have a clear tendency to cooperate in a one-shot situation act like freeriders as soon as they are the only team member with a temporary contract. Thus, not only the limitation of interaction frequency itself has a considerable effect on cooperation but also the diversity of the team regarding group membership. Possible implications for organizations are (i) that temporary group memberships may have detrimental effects on cooperation wherever teamwork is essential and (ii) that a particular diversity with regard to types of group membership should be carefully taken into consideration when assigning employees to work groups. When composing new teams, the ratio of different types of employees needs to be taken into account and managers should be careful when putting one agent alone in the position of an outsider. Concerning the mixed findings on temporary employment for instance, our results show that the specific team composition in which a temp is employed matters in order to determine whether she will refuse to cooperate because of her situation in the team or not.

Moreover, we suggest that diversity in group membership may be integrated in research of multidimensional diversity discussed as faultlines (e.g. Lau and Murnighan 1998, van Knippenberg and Schippers 2007, Homan et al. 2008). The vast majority of research on team diversity has focused either on individual differences, such as ethnicity, gender, and age, or on occupational differences, such as functions, and areas of expertise (see, for an extensive review, Joshi and Roh 2009). Our results reveal that diversity in team membership, neglected so far, plays an important role. The acceptance of diversity in team membership may depend on the prevalence of other diversity-dimensions. Therefore, conflicts, group cohesion, and performance may be affected by the interaction of heterogeneity in group memebership with other diversity dimensions such as age or pay. 


\section{References}

Akerlof G, Kranton R (2000) Economics and Identity. Quarterly Journal of Economics 115(3):715-753.

Andreoni J (1988) Why free ride?: Strategies and learning in public goods experiments. Journal of Public Economics 37(3):291-304.

Andreoni J, Harbaugh W, Vesterlund L (2003) The carrot or the stick: Rewards, punishments, and cooperation. American Economic Review 93(3):893-902.

Angelova V, Güth W, Kocher M (2012) Co-employment of permanently and temporarily employed agents. Labour Economics 19(1):48-58.

Arvanitis S (2005) Modes of labor flexibility at firm level: Are there any implications for performance and innovation? Evidence for the Swiss economy. Industrial and Corporate Change 14(6):993-1016.

Bakker R (2010) Taking stock of temporary organizational forms : a systematic review and research agenda. International Journal of Management Reviews 12(4):466-486.

Bartel A, Ichniowski C, Shaw K (2007) How Does Information Technology Affect Productivity? Plant-Level Comparisons of Product Innovation, Process Improvement, and Worker Skills. Quarterly Journal of Economics 122(4):1721-1758.

Bentolila S, Bertola G (1990) Firing costs and labour demand: how bad is eurosclerosis? The Review of Economic Studies 57(3):381-402.

Bentolila S, Saint-Paul G (1994) A model of labor demand with linear adjustment costs. Labour Economics 1(3-4):303-326.

Bloom N, van Reenen J (2007) Measuring and Explaining Management Practices Across Firms and Countries. Quarterly Journal of Economics 122(4):1351-1408.

Boeri T, Garibaldi P (2007) Two Tier Reforms of Employment Protection: A Honeymoon Effect? Economic Journal 117(521):F357-F385.

Böhm R, Rockenbach B (2013) The inter-group comparison-intra-group cooperation hypothesis: Comparisons between groups increase efficiency in public goods provision. PloS one 8(2): e56152.

Boone C, Hendriks W (2009) Top Management Team Diversity and Firm Performance: Moderators of Functional-Background and Locus-of-Control Diversity. Management Science 55(2):165-180.

Booth A (1997): An Analysis of Firing Costs and their Implications for Unemployment Policy. Snower D, de la Dehesa G, eds. Unemployment Policy (Cambridge University Press), 395-388. 
Booth A, Francesconi M (2002) Temporary Jobs: Stepping Stones or Dead Ends? Economic Journal 112(480):F189-F213.

Brandts J, Saijo T, Schram A (2004) How universal is behavior? A four country comparison of spite and cooperation in voluntary contribution mechanisms. Public Choice 119(3-4): 381-424.

Brosig J (2002) Identifying cooperative behavior: some experimental results in a prisoners dilemma game. Journal of Economic Behavior and Organization 47:275-290.

Brosig J, Ockenfels A, Weimann J (2003) The effect of communication media on cooperation. German Economic Review 4:217-241.

Burlando R, Hey J (1997) Do Anglo-Saxons free-ride more? Journal of Public Economics 64(1):41-60.

Burlando R, Guala F (2005) Heterogeneous agents in public goods experiments. Experimental Economics $8(1): 35-54$.

Chan K, Mestelmann S, Moir R, Muller R (1999) Heterogeneity and the voluntary provision of public goods. Experimental Economics 2(1):5-30.

Charness G, Rigotti L, Rustichini A (2007) Individual behavior and group membership. The American Economic Review 97(4):1340-1352.

ChenY, Li S (2009) Group Identity and Social Preferences. American Economic Review 99(1):431-457.

Cherry T, Kroll S, Shogren J (2005) The impact of endowment heterogeneity and origin on public good contributions: evidence from the lab. Journal of Economic Behavior \& Organization 57(3):357-365.

Croson R (1996) Partners and strangers revisited. Economics Letters 53(1):25-32.

Cummings, J (2004) Work groups, structural diversity, and knowledge sharing in a global organization. Management Science 50(3):352-364.

De Cuyper N, De Jong J, De Witte H, Isaksson K, Rigotti T, Schalk R (2008) Literature Review of Theory and Research on the Psychological Impact of Temporary Employment: Towards a Conceptual Model. International Journal of Management Reviews 10(1):25-51.

De la Rica S (2004) Wage gaps between workers with indefinite and fixed-term contracts: The impact of firm and occupational segregation. Moneda y crédito: revista de economía 219:43-69.

Dertouzo J, Karoly L (1992) Labor market responses to employer liability (Santa Monica, Calif.: Rand).

Dolado J, Stucchi R (2008) Do temporary contracts affect Total Factor Productivity? Evidence from Spanish manufacturing firms. CEPR Discussion Paper DP7055. 
Dufwenberg M, Gächter S, Hennig-Schmidt H (2011) The framing of games and the psychology of play. Games and Economic Behavior 73(2):459-478

Eckel C, Grossmann P (2005) Managing Diversity by Creating Team Identity. Journal of Economic Behavior and Organization 58(3):371-391.

Eriksson T, Ortega J (2006) The adoption of job rotaton: Testing the theories. Industrial and labor relations review 59(4):653-666.

Fehr E, Gächter S (2000) Cooperation and punishment in public goods experiments. American Economic Review 90(4):980-994.

Fischbacher U (2007) z-Tree: Zurich Toolbox for Ready-made Economic Experiments. Experimental Economics 10(2):171-178.

Fischbacher U, Gächter S (2006) Heterogeneous social preference and the dynamics of free riding in public goods. CeDEx Discussion Paper 2006-01, The University of Nottingham, Nottingham.

Fischbacher U, Gächter S (2010) Social preferences, beliefs, and the dynamics of free riding in public goods experiments. The American Economic Review 100(1):541-556.

Fischbacher U, Gächter S, Fehr E (2001) Are people conditionally cooperative? Evidence from a public goods experiment. Economics Letters 71(3):397-404.

Fischbacher U, Schudy S, Teyssier S (2012) Heterogeneous reactions to heterogeneity in returns from public goods. Social Choice and Welfare 43(1):1-23.

Gagliarducci S (2005) The dynamics of repeated temporary jobs. Labour Economics 12(4):429-448.

Goette L, Huffman D, Meier S (2006) The impact of group membership on cooperation and norm enforcement: Evidence using random assignment to real social groups. American Economic Review 96(2):212-216.

Goux D, Maurin E, Pauchet M (2001) Fixed-term contracts and the dynamics of labour demand. European Economic Review 45(3):533-552.

Greiner B (2004) The Online Recruitment System ORSEE - A Guide for the Organization of Experiments in Economics. Papers on Strategic Interaction 2003-10, Max Planck Institute of Economics, Strategic Interaction Group.

Heinrich C, Mueser P, Troske K (2005) Welfare to temporary work: Implications for labor market outcomes. Review of Economics and Statistics 87(1):154-173. 
Homan A, Hollenbeck J, Humphrey S, van Knippenberg D, Ilgen D, van Kleef G (2008) Facing Differences With an Open Mind: Openness to Experience, Salience of Intragroup Differences, and Performance of Diverse Work Groups. Academy of Management Journal 51(6):1204-1222.

Hoogendoorn S, Oosterbeek H, van Praag M (2013) The Impact of Gender Diversity on the Performance of Business Teams: Evidence from a Field Experiment. Management Science 59(7):1514-1528.

Isaac R, Walker J, Williams A (1994) Group size and the voluntary provision of public goods: experimental evidence utilizing large groups. Journal of Public Economics 54(1):1-36.

Joshi A, Roh H (2009) The Role Of Context In Work Team Diversity Research: A Meta-Analytic Review. Academy of Management Journal 52(3):599-627.

Kagel J, and Roth A (1995) The handbook of experimental economics. Princeton University Press, Princeton, NJ.

Kalleberg A (2000) Nonstandard employment relations: Part-time, temporary and contract work. Annual review of sociology 2000:341-365.

Kavadias S, Sommer S (2009) The effects of problem structure and team diversity on brainstorming effectiveness. Management Science 55(12):1899-1913.

Keser C, Van Winden F (2000) Conditional cooperation and voluntary contributions to public goods. Scandinavian Journal of Economics 102(1):23-39.

Kocher M, Cherry T, Kroll S, Netzer R, Sutter M (2007) Conditional cooperation on three continents. Economic Letters 101(3):175-178.

Lau D, Murnighan J (1998) Demographic Diversity and Faultlines: The Compositional Dynamics of Organizational Groups. Academy of Management Journal 23(2):325-340.

Michie J, Sheehan-Quinn M (2001) Labour Market Flexibility, Human Resource Management and Corporate Performance. British Journal of Management 12:287-306.

Montmarquette C, Rullière J, Villeval M, Zeiliger R (2004) Redesigning teams and incentives in a merger: An experiment with managers and students. Management Science 50(10):1379-1389.

Niederle M, Segal C, Vesterlund L (2013) How costly is diversity? Affirmative action in light of gender differences in competitiveness. Management Science 59(1):1-16.

OECD (2014): Online OECD Employment database.

http://www.oecd.org/els/emp/onlineoecdemploymentdatabase.htm. 
Ohana M (2011) Horizontal Social Comparisons and Vertical Reciprocity in a Principal-Multi-Agent Experiment. Bulletin of Economic Research 63(3):243-254.

Ortega J (2001) Job rotation as a learning mechanism. Management Science 47(10):1361-1370.

Palfrey T, Prisbrey J (1996) Altuism, reputation and noise in linear public goods experiments. Journal of Public Economics 61(3):409-427.

Rustagi D, Engel S, Kosfeld M (2010) Conditional cooperation and costly monitoring explain success in forest commons management. Science 330(6006):961-965.

Saunders C, Ahuja K (2006) Are all distributed teams the same? Differentiating between temporary and ongoing distributed teams. Small Group Research 37(6):662-700.

Selten R (1967) Die Strategiemethode zur Erforschung des eingeschränkt rationalen Verhaltens im Rahmen eines Oligopolexperiments. Sauermann $\mathrm{H}$, eds. Beiträge zur experimentellen Wirtschaftsforschung (Tübingen:Mohr): 136-168.

Sonnemans J, Schram A, Offerman T (1999) Strategic behavior in public good games: when partners drift apart. Economics Letters 62(1):35-41.

Tajfel H, Turner J (1979) An Integrative Theory of Intergroup Conflict. In Worchel S, Austin W, eds. The Social Psychology of Intergroup Relations (Chicago Nelson-Hall).

Van Knippenberg D, Schippers M (2007) Work Group Diversity. Annual Review of Psychology 58:515-541.

Weimann J (1994) Individual behaviour in a free riding experiment. Journal of Public Economics 54(2): 185-200.

Wuchty S, Jones B, Uzzi B (2007) The Increasing Dominance of Teams in Production of Knowledge. Science 316(5827):1036-1039. 
APPENDIX A.1: Alternative tobit regressions on individual contributions (Round 1 to 10) with number of team members that are of the same type as a dummy

\begin{tabular}{|c|c|c|c|c|c|c|}
\hline & I & II & III & IV & $\mathbf{V}$ & VI \\
\hline Temp & $\begin{array}{l}-2.572 * * \\
(1.256)\end{array}$ & $\begin{array}{l}-2.655^{* *} \\
(1.219)\end{array}$ & $\begin{array}{l}-5.127^{* * *} \\
(1.636)\end{array}$ & $\begin{array}{l}-2.719 * * \\
(1.067)\end{array}$ & $\begin{array}{l}-1.997 * \\
(1.112)\end{array}$ & $\begin{array}{l}-1.739 * \\
(1.042)\end{array}$ \\
\hline \multicolumn{7}{|l|}{ \# same type team mates (reference $=0$ ) } \\
\hline 1 & $\begin{array}{l}1.604 \\
(1.278)\end{array}$ & $\begin{array}{l}1.343 \\
(1.235)\end{array}$ & $\begin{array}{l}1.105 \\
(1.193)\end{array}$ & $\begin{array}{l}5.009 * * * \\
(0.994)\end{array}$ & $\begin{array}{l}3.445^{* * * *} \\
(1.101)\end{array}$ & $\begin{array}{l}4.501^{* * * *} \\
(1.041)\end{array}$ \\
\hline 2 & $\begin{array}{l}3.031 \\
(2.044)\end{array}$ & $\begin{array}{l}2.569 \\
(2.089)\end{array}$ & $\begin{array}{l}2.310 \\
(2.018)\end{array}$ & $\begin{array}{l}6.585^{* * *} \\
(1.228)\end{array}$ & $\begin{array}{l}4.337 * * * \\
(1.346)\end{array}$ & $\begin{array}{l}5.934 * * * \\
(1.198)\end{array}$ \\
\hline 3 & $\begin{array}{l}4.224^{* * *} \\
(1.141)\end{array}$ & $\begin{array}{l}3.706 * * * \\
(1.107)\end{array}$ & $\begin{array}{l}3.444^{* * *} \\
(1.066)\end{array}$ & $\begin{array}{l}5.547 * * * \\
(0.905)\end{array}$ & $\begin{array}{l}3.683^{* * *} \\
(1.017)\end{array}$ & $\begin{array}{l}4.793^{* * *} \\
(0.955)\end{array}$ \\
\hline Conditional willingness to cooperate & & $\begin{array}{l}3.603^{* * *} \\
(1.205)\end{array}$ & $\begin{array}{l}2.470 \\
(1.659)\end{array}$ & $\begin{array}{l}1.363 \\
(1.037)\end{array}$ & $\begin{array}{l}0.871 \\
(1.047)\end{array}$ & $\begin{array}{l}1.027 \\
(1.025)\end{array}$ \\
\hline Conditional cooperation $*$ Temp & & & $\begin{array}{l}3.613 * * \\
(1.908)\end{array}$ & $\begin{array}{l}3.419 * * \\
(1.360)\end{array}$ & $\begin{array}{l}3.290 * * \\
(1.351)\end{array}$ & $\begin{array}{l}3.066^{* *} \\
(1.326)\end{array}$ \\
\hline Belief about team mates contribution & & & & $\begin{array}{l}1.461^{* * *} \\
(0.069)\end{array}$ & & $\begin{array}{l}1.006^{* * *} \\
(0.080)\end{array}$ \\
\hline Team mates' contr. precedent round & & & & & $\begin{array}{l}1.457 * * * \\
(0.077)\end{array}$ & $\begin{array}{l}0.605^{* * *} \\
(0.095)\end{array}$ \\
\hline Round & $\begin{array}{l}-1.465^{* * *} \\
(0.120)\end{array}$ & $\begin{array}{l}-1.457 * * * \\
(0.119)\end{array}$ & $\begin{array}{l}-1.458^{* * *} \\
(0.119)\end{array}$ & $\begin{array}{l}-0.349 * * * \\
(0.071)\end{array}$ & $\begin{array}{l}-0.149 * \\
(0.079)\end{array}$ & $\begin{array}{l}-0.087 \\
(0.073)\end{array}$ \\
\hline Constant & $\begin{array}{l}6.838 * * * \\
(1.472)\end{array}$ & $\begin{array}{l}4.908^{* * *} \\
(1.479)\end{array}$ & $\begin{array}{l}5.931^{* * *} \\
(1.608)\end{array}$ & $\begin{array}{l}-11.53^{* * *} \\
(1.561)\end{array}$ & $\begin{array}{l}-10.02^{* * *} \\
(1.588)\end{array}$ & $\begin{array}{l}-12.99 * * * \\
(1.558)\end{array}$ \\
\hline Observations & 3,360 & 3,360 & 3,360 & 3,360 & 3,024 & 3,024 \\
\hline Pseudo $\mathrm{R}^{2}$ & 0.030 & 0.034 & 0.035 & 0.122 & 0.096 & 0.118 \\
\hline
\end{tabular}


APPENDIX A.2: Alternative tobit regressions on individual contributions (Round 1 to 10) with individual preferences in one-shot public goods according to Rustagi et al. (2010) ${ }^{9}$

\begin{tabular}{|c|c|c|c|}
\hline & I & II & III \\
\hline Temp & $\begin{array}{l}-8.146^{* * *} \\
(2.413)\end{array}$ & $\begin{array}{l}-0.963 * \\
(0.513)\end{array}$ & $\begin{array}{l}-13.021^{* * *} \\
(2.876)\end{array}$ \\
\hline \# same type team mates & $\begin{array}{l}0.571^{* *} \\
(0.267)\end{array}$ & $\begin{array}{l}-0.638 \\
(0.965)\end{array}$ & $\begin{array}{l}-3.059 * * \\
(1.232)\end{array}$ \\
\hline \multicolumn{4}{|c|}{ Type of preference (reference = freerider) } \\
\hline Strong cooperator & $\begin{array}{l}4.411 * * * \\
(1.522)\end{array}$ & $\begin{array}{l}4.315^{* *} \\
(2.006)\end{array}$ & $\begin{array}{l}-4.069 \\
(2.734)\end{array}$ \\
\hline Weak cooperator & $\begin{array}{l}7.884^{* *} \\
(3.232)\end{array}$ & $\begin{array}{l}5.071 \\
(3.160)\end{array}$ & $\begin{array}{l}1.119 \\
(4.294)\end{array}$ \\
\hline Others & $\begin{array}{l}5.772 * * * \\
(1.947)\end{array}$ & $\begin{array}{l}2.398 \\
(2.370)\end{array}$ & $\begin{array}{l}-6.096 * * \\
(3.123)\end{array}$ \\
\hline Strong cooperator * temp & $\begin{array}{l}8.238 * * * \\
(2.544)\end{array}$ & --- & $\begin{array}{l}13.207^{* * *} \\
(2.987)\end{array}$ \\
\hline Weak cooperator * temp & $\begin{array}{l}1.644 \\
(4.021)\end{array}$ & --- & $\begin{array}{l}6.222 \\
(4.351)\end{array}$ \\
\hline Others * temps & $\begin{array}{l}7.652 * * \\
(3.034)\end{array}$ & --- & $\begin{array}{l}13.388^{* * *} \\
(3.269)\end{array}$ \\
\hline $\begin{array}{l}\text { Strong cooperator *\# same type team } \\
\text { mates }\end{array}$ & --- & $\begin{array}{l}1.245 \\
(0.990)\end{array}$ & $\begin{array}{l}3.817 * * * \\
(1.272)\end{array}$ \\
\hline $\begin{array}{l}\text { Weak cooperator * \# same type team } \\
\text { mates }\end{array}$ & --- & $\begin{array}{l}1.405 \\
(1.512)\end{array}$ & $\begin{array}{l}3.028^{*} \\
(1.636)\end{array}$ \\
\hline Others * \# same type team mates & --- & $\begin{array}{l}2.656^{* *} \\
(1.250)\end{array}$ & $\begin{array}{l}5.230 * * * \\
(1.483)\end{array}$ \\
\hline Belief about team mates contribution & $\begin{array}{l}0.924 * * * \\
(0.076)\end{array}$ & $\begin{array}{l}0.909 * * * \\
(0.075)\end{array}$ & $\begin{array}{l}0.927 * * * \\
(0.075)\end{array}$ \\
\hline Team mates' contr. precedent round & $\begin{array}{l}0.597 * * * \\
(0.088)\end{array}$ & $\begin{array}{l}0.597 * * * \\
(0.090)\end{array}$ & $\begin{array}{l}0.585^{* * *} \\
(0.089)\end{array}$ \\
\hline Round & $\begin{array}{l}-0.159 * * \\
(0.074)\end{array}$ & $\begin{array}{l}-0.169 * * \\
(0.074)\end{array}$ & $\begin{array}{l}-0.172 * * \\
(0.075)\end{array}$ \\
\hline Constant & $\begin{array}{l}-11.626^{* * *} \\
(1.734)\end{array}$ & $\begin{array}{l}-11.134^{* * *} \\
(2.144)\end{array}$ & $\begin{array}{l}-3.448 \\
(2.621)\end{array}$ \\
\hline Observations & 3024 & 3024 & 3024 \\
\hline Pseudo R2 & .1275 & .1247 & .1308 \\
\hline
\end{tabular}

Notes: Robust and clustered standard errors of 84 groups. ${ }^{* * *} \mathrm{p}<0.01,{ }^{* *} \mathrm{p}<0.05,{ }^{*} \mathrm{p}<0.1$.

\footnotetext{
${ }^{9}$ Rustagi, Devesh, Stefanie Engel, and Michael Kosfeld. "Conditional cooperation and costly monitoring explain success in forest commons management." Science 330.6006 (2010): 961-965; A similar approach also in: Fischbacher, Urs, Simon Gächter, and Ernst Fehr. "Are people conditionally cooperative? Evidence from a public goods experiment." Economics Letters 71.3 (2001): 397-404.
} 


\section{APPENDIX B}

\section{Experimental Instruction (originally in German)}

Welcome and thank you for participating in this experiment. If you read the following instructions carefully, you can, depending on your decisions, earn a considerable amount of money. It is therefore very important that you read these instructions with care.

The instructions which we have distributed to you are solely for your private information. It is prohibited to communicate with the other participants during the experiment. Please make sure that you switched off your mobile devices. Should you have any questions, please ask us. If you violate this rule, we shall have to exclude you from the experiment and from all payments.

During the experiment, we will not speak of Euros but rather of points. During the experiment your entire earnings will be calculated in ECU (Experimental Currency Units). At the end of the experiment the total amount of ECUs you have earned will be converted to Euros at the following rate:

\section{$1 \mathrm{ECU}=0.15 €$}

Your earning plus a show-up fee of 3 Euros will be paid cash to you after the experiment.

Nobody will learn about your earnings or your decisions. Please do also not discuss your decisions with other participants after the experiment.

\section{The decision situation}

You will learn later on how the experiment will be conducted. We first introduce you to the basic decision situation. At the end of the description of the decision situation, you will find control questions that will help you to gain an understanding of the decision situation.

You will be a member of a group of 4 people. Each member has to decide on the division of 20 ECUs. You can put these 20 ECUs on a private account or you can invest them fully or partially into a project. Each ECU you do not invest into the project will automatically be transferred to your private account.

\section{Your income from the private account}

For each ECU you put on your private account you will earn exactly one point. For example, if you put twenty ECUs on your private account (which implies that you do not invest anything into the project) you will earn exactly twenty ECUs from the private account. If you put 6 ECUs into the private account, you will receive an income of 6 ECUs from the private account. Nobody except you earns something from your private account.

\section{Your income from the project}

From the ECU amount you invest into the project each group member will get the same payoff. Of course, you will also get a payoff from the ECUs the other group members invest into the project. Each ECU that is invested into the project will be multiplied by 1.6 and be equally distributed among all members of a group. That means that for each ECU invested in the project every member earns 0.4 ECUs, no matter which member of the group invested the ECU. For each group member the income from the project will be determined as follows:

$$
\text { Income from the project }=\text { sum of contributions to the project } \mathrm{x} 0.4
$$

For example, if the sum of all contributions on the project is 60 ECUs, then you and all other group members will get a payoff of $60 \times 0.4=24$ ECUs from the project. If the four group members together contribute 10 ECUs to the project, you and all others will get a payoff of 10 x $0.4=4$ ECUs from the projects.

Your total income

Your total income results from the summation of your income from the private account and your income from the project.

$$
\begin{gathered}
\text { Income from the private account } \\
(=20-\text { Contribution to the project }) \\
+ \\
\text { Income from the project } \\
=0.4 \times \text { Sum of contributions to the project }) \\
= \\
\text { Total income }
\end{gathered}
$$




\section{Control questions}

Please answer the following control questions. Their purpose is to make your familiar with the calculation of the incomes that accrue from different decisions about allocation of 20 ECUS.

1. Each group member has 20 ECUs in his or her disposal. Assume that none of the four group members (including you) contributes anything to the project. What will your total income be? ECUs

What is the total income of the other group members? ECUs

2. Each group member has 20 ECUs at his or her disposal. Assume that you invest 20 ECUs into the project and each of the other group members also invests 20 ECUs. What will be your total income?

ECUs

What is the total income of the other group members?

ECUs

3. Each group member has 20 ECUs at his or her disposal. Assume that the other three group members together contribute 30 ECUs to the project.

What is your total income if you - in addition to the 30 ECUs - contribute 0 ECUs to the project? ECUs

What is your total income if you - in addition to the 30 ECUs - contribute 15 ECUs to the project? ECU

If you finish these questions before the others, we advise you to think about the additional examples to further familiarize yourself with the decision situation.

\section{The experiment - part 1}

This part of the experiment contains the decision situation that we have just described to you. At the end of the experiment you will get paid according to the decisions you make in this experiment. The experiment will only be conducted once.

As you know you will have 20 ECUs at your disposal. You can put them into a private account or you can invest them into a project. In this experiment each subject has to make two types of decisions. In the following we will call them "unconditional contribution" and "contribution table“.

\section{"Unconditional contribution"}

With the unconditional contributions to the project you have to decide how many of the 20 ECUs you want to invest into the project.

After you have determined your unconditional contribution you press the "OK”-button.

\section{“Contribution table“}

Your second task is to fill out a "contribution table“. In the contribution table you have to indicate for each possible average contribution of the other group members (rounded to the next integer) how many ECUs you want to contribute to the project. You can condition your contribution on the contribution of the other group members.

The numbers next to the input boxes are the possible (rounded) average contribution of the other group members to the project. You simply have to insert into each input box how many ECUs you will contribute to the project conditional on indicated average contribution. You have to make an entry into each input box. For example, you will have to indicate how much you contribute to the project if the others contribute 0 ECUs to the project, how much you contribute if the others contribute 1, 2 or 3 ECUs etc. In each input box you can insert all integer numbers from 0 to 20. If you have made an entry in each input box, press the "OK”-button. 


\section{Income}

After all participants of the experiment have made an unconditional contribution and filled out their contribution table, in each group a random mechanism will select a group member.

For the randomly determined subject only the contribution only the contribution table will be the payoff-relevant decision. For the other three group members who are not selected by the random mechanism, only the unconditional contribution will be the payoff-relevant decision. When you make your unconditional contribution and when you fill out the contribution table you of course do not know whether you will be selected by the random mechanism. You will therefore have to think carefully about both types of decisions because both can become relevant for you.

The random selection of the participants will be implemented as follows. Each group member is assigned a number between 1 and 4 . One individual will be randomly selected by the computer. For this individual, the chosen number in the contribution table will determine the pay off. For the other three (non-selected) individuals, the chosen number from the unconditional contribution will be relevant for the pay offs.

Please raise your hand if you have any questions about the experiment, we will then come to you to answer your questions. When no participant still has any questions we will start the computer program. Please wait quietly in your seat after you have made you decision as more tasks will follow shortly.

\section{The experiment - part 2}

In the following experiment you will again be asked to make a decision as described above. You will again have 20 ECUs at your disposal and you have to decide how much you want to contribute to the project. The ECUs that you do not invest will be transferred to your private account.

Your income will again be calculated as follows:

$$
\begin{gathered}
\text { Income from your private account } \\
(=20-\text { contribution to the project }) \\
+ \\
\text { Income from the project } \\
(=0.4 \times \text { Sum of contributions to the project }) \\
= \\
\text { Total income }
\end{gathered}
$$

The following experiment will be played for 10 rounds. You will therefore be asked to decide on how to invest your 20 ECUs 10 times in a row.

Before part 2 starts, all groups will be recombined by a random mechanism. That means that

you will form a group with participants who you have not been in a group with before. A group consists of players A, B, C and D.

There are 2 types of group members: type $\mathrm{X}$ and type $\mathrm{Y}$. Type $\mathrm{X}$ players will always stay in a group while a type $\mathrm{Y}$ players changes groups after each round. The screen will inform you about your own allocated type as well as the types of the other members in the group.

Please insert into each input box how many ECUs you want to invest into the project and press "OK" to confirm. After each of your contribution decisions you will be asked to estimate how many ECUs each of your group members invested into the project.

The contribution table in which you will enter your estimates will look like this:

\begin{tabular}{|l|l|l|l|l|}
\hline Player & A & B & C & D \\
\hline Type of player & X & X & X & Y \\
\hline Estimate & YOU & {[]} & {[]} & {[]} \\
\hline
\end{tabular}

In addition the program will indicate the average value of your estimates. Please confirm your estimates with "OK".

If you make a good estimate, you will receive an income. This income is the result of 10 ECUs minus the deviation of your estimate and the actual average:

$$
\text { Income }=10 \text { ECUs }-\mid \text { deviation } \mid \text {. }
$$


If your estimate was wrong by 10 ECUs or more, you will not receive any income. However, no ECUs will be taken from you, which implies that you cannot lose anything at this point.

Your income from the estimate will be transferred to your private account but you cannot invest these ECUs in the following rounds. Regardless of your estimate you will again have 20 ECUs in the next round that your can invest.

At the end of the second part a participant will randomly draw a piece of paper with a number between 1 and 10 from an urn. The number that is drawn indicates the round that will be payoff-relevant for this experiment. If for example a participant draws a piece of paper with the number "3" from the urn, your result from the third round is payoff-relevant.

Please raise your hand if you have any questions about the experiment, we will then come to you to answer your questions. When no participant still has any questions we will start the computer program. Please wait quietly in your seat after you have made you decision as more tasks will follow shortly.

\section{The experiment - part 3}

In the third part of the experiment you will be asked to again decide on how to allocate the amount of 20 ECUs. Your income will be calculated in exactly the same way as in the second part of the experiment. You will again play for 10 rounds and asked to decide on how to invest your 20 ECUs 10 times in a row.

You will keep the same letter as in the experiment before, so if you e.g. were a Player 'B' during the last part, you will be again a player ' $\mathrm{B}$ '.

There will be again two types of players: type $X$ and type $Y$. Players of type $X$ will be in the group as in the second part of the experiment. Players of type $X$ will again stray in their groups. Players of type $\mathbf{Y}$ will change into a new group after each round. The screen will inform you about your own allocated type as well as the types of the other members in the group.

This experiment will also be played for 10 rounds. Between the rounds you will once again be asked to estimate how much the other group members contributed to the project. Your income for your estimate is calculated just as in the second part of the experiment.

After 10 rounds drawing a number from an urn will determine which of the 10 rounds will be payoff-relevant.

Please raise your hand if you have any questions about the experiment, we will then come to you to answer your questions. When no participant still has any questions we will start the computer program. Please wait quietly in your seat after you have made you decision as more tasks will follow shortly.

\section{The experiment - part 4}

This part of the experiment consists of two subsequent parts: part A and part B. In both parts you will have to decide several times between two alternatives I (left) and II (right). Each part of the game consists of a total of 22 decisions, each represented in a different line.

Attention: You will always choose from alternative I (left) and II (right). However, they will be different options in part $A$ and $B$. In part $A$ and part $B$ you can only switch between left and right.

Payoff-relevant decision

There are two roles a player can take: player 1 and player 2. After all decisions have been made, your role -1 or 2 will be randomly selected. At the same time, you will randomly be given a partner of the opposite role, which means pairs will always contain a player 1 and a player 2. Pairs can consist of participants from your group in part 1-3 $\mathrm{f}$ the experiment or from participants from other groups. However, you will not be told who your partner is and whether he or she comes from your group or another group.

Next, it will be randomly determined whether a pair will play part A or part B of the experiment and which of the 22 decisions of part $\mathrm{A}$, respectively part $\mathrm{B}$, are payoff-relevant.

If you are player 1 , your decision in the line drawn by lot will be payoff-relevant for you and your partner. Your partner as player 2 will have to accept this decision. If you are player 2, the decisions of your partner will be payoffrelevant for you and your partner. In this case, you as player 2 will have to accept this decision.

Attention: Your decision will only have an influence on your and your partner's income if you are chosen as player 1. If you are chosen as player 2 , your decision is irrelevant.

\section{After the experiments}

You have now participated in all parts of the experiment. We now ask you to please fill in a short questionnaire at the computer. After filling out the questionnaire you will see a screen that will indicate how much earned altogether. Please stay quietly in your seat until we call you. We will then pay you in cash. 